\title{
Distribution of Resources to Panhandlers as a Male Display of Potential Mate Quality
}

\author{
Amy Webb ${ }^{1}$ \& Maryanne L. Fisher ${ }^{2}$ \\ ${ }^{1}$ Human Sexuality Research Laboratory, School of Psychology, University of Ottawa, Canada \\ ${ }^{2}$ Department of Psychology, Saint Mary’s University, Halifax, Canada
}

awebb069@uottawa.ca

\begin{abstract}
Evolutionary psychological theory predicts that because women generally prefer men with resources, men will display their generosity and wealth in order to gain positive attention from potential mates. Therefore, the goal of the current study was to examine men's displays of generosity and wealth in the presence versus absence of women. We hypothesized that men would donate money or other items most often in the presence of women, compared to while walking alone or in the presence of other men. We performed observations along busy pedestrian streets in Atlantic Canada, and documented the frequency with which men stopped to provide money or items to those begging ("panhandling") for resources. Our results supported our hypothesis, as men significantly donated money or other items more often while walking in the presence of a woman, as compared to any other condition. We propose that men are using this display of generosity and wealth to signal positive attributes to potential mates. This finding offers a new avenue in which to test theories regarding mate preferences in a natural setting.
\end{abstract}

Keywords: Mate preferences, Resources, Ethology, Mate quality, Observation. 


\section{INTRODUCTION}

Sex differences in theories surrounding mate preferences indicate that women generally prefer men with resources. One explanation for this preference stems from parental investment theory. The evolution of anisogamy (i.e., sexual reproduction with unequal size of gametes) leads to the possibility that women are the more investing sex because of disproportionate costs related to their gametes, gestation, and postpartum childcare (Trivers, 1972; but see also Fisher, Garcia, \& Burch, in press, for a review of criticisms). While men's reproductive success is thought to be largely determined by their number of copulations, women's reproductive success relies on their investments of time and energy during conception, gestation, and post-partum childcare (Campbell, 1999; Trivers, 1972). Women's substantial parental investment causes them to have a deficit in securing adequate resources for themselves and/or their children, leading them to theoretically rely on men's resources and efforts to aid with children. Past research indicates women are typically much choosier than men when selecting a mate (e.g., Walters \& Crawford, 1994), and overall, express a preference for men who can provide care, have the ability and willingness to invest resources, and contribute support for both them and their children (e.g., Buss 1989; Lu, Zhu, \& Chang, 2015).

Sexual selection theory (Darwin, 1871) leads to the premise that to experience reproductive success, individuals need to out perform potential rivals for mates while also appearing the most appealing to members of the opposite sex. Therefore, individuals may endeavor to appear the best, compared to others of the same sex, in the hopes that they are selected for mating. The traits that lead to this evaluation by potential mates are the same as those involved in mating competition (Andersson, 1994), which leads to difficulties in trying to tease apart whether an individual is displaying a preferred mating-relevant characteristic to court a potential mate or to win against rivals, or both. Recent developments indicate that for men, intrasexual competition more than women's mate preferences seem to have a larger role in shaping physical dominance (Kordsmeyer, Hunt, Puts, Ostner, \& Penke, 2018). Either way, these individuals who are high on these preferred traits have evolved a reproductive advantage (Buss \& Schmitt, 1993).

Men significantly vary in the specific qualities that women find appealing, particularly when being considered as a prospective long-term mate (Buss \& Schmitt, in press). In a long-term mating situation, men are more likely to provide food, find or defend territories, feed and protect children, and perhaps provide opportunities for status transfer, power, or other resources (Buss, 1989; Buss \& Schmitt, 1993). Women consider a number of observable cues to judge whether a man is a desirable long-term mate (Buss \& Schmitt, 1993). One of the most important signals of his mate quality is his ability to distribute resources, or whether he possesses traits that indicate future accrual of resources, such as ambition, industriousness, and being a hard worker (e.g., Buss, 1989).

Ultimately, women generally benefit if they are able to identify potential mates who are both willing and able to invest resources to them and their children, given the potential deficits they will face in accruing independent resources. It is highly important for women to observe such cues as ambition, industry, income, status, and generosity, as these characteristics are correlated with a man's ability and willingness to invest (Buss \& Schmitt, 1993). Thus, the current study is an examination of whether men display 
generosity and wealth via sharing their resources while in the presence of women, if given the opportunity.

We observed men's interactions with individuals asking for money (hereon called panhandlers). Panhandlers are people who publicly request money, food, or other donations from people they do not know (Lee \& Farrell, 2003), and most are not homeless (Dordick et al., 2017). They exist universally, and have likely existed across all of time (Verma, Bharti, \& Singh, 2018). Across a range of locations (e.g., Brussels, Toronto, Moscow, Shanghai, and London), panhandlers typically earn an average hourly income comparable to minimum wage in that location (see Dordick et al., 2017, for a review). Often, they request money or other items with little or nothing to give the donor in return. Panhandlers typically situate themselves in locations of high public traffic where money may be readily at hand, meaning that while most poor individuals try to hide their poverty, panhandlers must flaunt it to be successful (Dordick et al., 2017). Indeed, in locations such as downtown Manhattan, over 10,000 people are thought to see a panhandler in one afternoon (Dordick et al., 2017).

The majority of panhandlers are men who have been forced into asking for money because of one or more negative life events (e.g., illness, accident) (Lee \& Farrell, 2003). The majority of panhandlers are substance abusers and due to this, often also have criminal records (Lee \& Farrell, 2003). There is a stereotype that they may also be at higher rates for violence or mental illness, although research does not support this belief (Lee \& Farrell, 2003; Tsai, Lee, Byrne, Pietrzak \& Southwick, 2017). Compared to 1990, recent national surveys about attitudes toward homeless individuals (including panhandlers) shows that Americans endorse more support for this group and an increase in compassion (Tsai, Lee, Byrne, Pietrzak \& Southwick, 2017). At the same time, there have been government movements to prohibit panhandling, which is counterproductive to alleviating homelessness, possibly because citizens experience a sense of disgust when they are in close proximity to those asking for money (Clifford, \& Piston, 2017).

Pandey et al. (2006) reported that panhandlers experience stigma and feel marginalized, dehumanized, discriminated against, and alienated, leading them to have negative views of their personal well-being. However, in some instances panhandlers appeared to enjoy the stigma because it directly led to increased donations of items. Due to the stereotypes about panhandlers, there exists a wide range of emotions and attitudes towards them as a group, including pity, fear, and anger (Lee \& Farrell, 2003).

For the purpose of the current study, panhandlers provide the opportunity for men to demonstrate their ability to distribute resources in front of potential mates. This display would show generosity and kindness (both considered preferred traits; Buss, 1989), but also that he possesses sufficient resources that he may give them away freely. Thus, we hypothesized that due to this behavior being relevant as a mating signal, men would be most likely to give panhandlers money or other items when in the presence of a woman, as compared to when they were with another man or alone. By extension, we also hypothesized that men who were walking alone would provide money and other items to panhandlers at the same rate as women walking alone. Similar findings were obtained by Iredale, Van Vugt, and Dunbar (2008); in an experimental game situation, men were more likely to donate a higher portion of earned money to charity when observed by women than by men, or with no observer. 


\section{METHODS}

\section{Context}

The studied individuals (hereby called "participants" although they were blind to their inclusion in the study) were observed in one of four conditions: (1) women walking alone past a panhandler, (2) men walking alone past a panhandler, (3) a man walking with another man past a panhandler, and (4) a man walking with a woman past a panhandler. Each individual was asked for change by an actual panhandler for that environment; they were not a confederate for the study. The consequences of their request were recorded by an observer discretely watching from a short distance away (e.g., inside a coffee shop or similar location). All observations were made as participants travelled along a sidewalk toward the panhandler, and neither the participants nor the panhandler were aware that they were being monitored. Observation ended once the participant walked past the panhandler.

Observations took place in several downtown locations of Halifax, Canada where panhandlers select areas of high pedestrian traffic. It was not possible to determine the nature of the items given to the panhandler without interfering with the interaction. Consequently, we established a simple criterion that a successful attempt at panhandling consisted of any item given by the pedestrian and placed into the hand or cup of the panhandler. We did observe that the majority of items consisted of coins (note that Canada has a 5, 10, 25 cent coin, as well as a 1 and 2 dollar coin).

Panhandlers were chosen based on the ability of the observer to remain hidden and undetected in a location of close proximity. Four separate panhandlers were watched in their interactions with pedestrians. All panhandlers were men, Caucasian, approximately 40-70 years old, were wearing clothes (i.e., large jackets and jeans) that appeared ripped and dirty, and were without a pet or sign asking for money. All panhandlers requested money verbally to pedestrians while remaining in a seated position.

Observations occurred over four days, for approximately three hours each day in total. Each day consisted of a different panhandler in a different location. All data collection occurred between January and March in the middle of a week day while there was no precipitation.

\section{Participants}

A total of 200 individuals were observed. We observed across the locations until we obtained a sample of 50 individuals in each of the four conditions. There were no exclusion criteria, as so long as the participants were of adult age (i.e., looked over the age of 20) and satisfied the criteria of the condition. Ethnicity varied, although we did notice that the majority of participants were either of Caucasian or Asian young adults.

We elected to systematically observe every second individual matching the condition criteria in order to allow the observer sufficient time after the event to complete the observation and record the result. Pedestrians were excluded if they were walking with more than one other adult for the dyad conditions, and excluded across all conditions if they were walking with an animal or child. Pedestrians were also excluded if they had to pass by another individual within a 5 meter radius around the panhandler (which we had 
marked inconspicuously while the panhandler was absent), as the presence of anyone other than those involved in the interaction could serve as a potential confounding variable.

Given the possibility of disgust in relation to panhandling, for the sake of interest we also recorded whether the pedestrian made physical contact with the panhandler (which we predicted would be a rare occurrence). We also recorded whether the pedestrian started use of an electronic device (e.g., a cellular telephone) while approaching the panhandler, presumably as a way to distract themselves from the interaction. We further observed whether they made direct eye contact or not with the panhandler. Other variables such as whether they stood in front of the panhandler or turned around while in close proximity (e.g., to change direction and avoid the interaction) was also recorded. Changes in gait speed were documented, given that we expected some individuals to speed up to avoid the interaction. We note that these changes had to be very clear in order to be observed reliably.

\section{RESULTS}

There are four independent conditions (i.e., male alone, female alone, male dyad, and female/male dyad) with a binary (yes/no) dependent variable, leading to a $4 \mathrm{X} 2$ contingency table. Due to the small number of cases (under 5) in all but the female/male dyad who did give an item to the panhandler, we decided to employ Fisher's exact test with the Monte Carlo approximation to determine significance. The comparison was significant, Fisher's exact test $=9.947, p=.015$ (99\% CI $=.012$ to .018 ; two-tailed, $\alpha=$. 05). Some readers may be interested in the Pearson Chi-square value (despite the minimum cell counts) with the Monte Carlo approximation; $\chi^{2}(3)=12.271, p=.006$ ( $99 \% \mathrm{CI}=.004$ to .008$)$. Table 1 provides the descriptive results.

Table 1: Percentage of Pedestrians Giving Item(s) to Panhandlers in Presence or Absence of Others

\begin{tabular}{ll}
\hline Condition & Percentage (\%) Gave Item(s) to Panhandler \\
\hline Female only & Current study \\
Male only & Tovée et al., 1997 \\
Male dyad & Tovée et al., 1997 \\
Female/male dyad & Voracek \& Fisher, 2006 \\
\hline
\end{tabular}

Note. Total sample size was 200, 50 per condition. 
Only 2 of the 200 participants touched the panhandler, both of them men such that one was walking alone, and the other in the male dyad condition. A total of $14.5 \%$ of pedestrians turned toward an electronic device when approaching the panhandler, $5.5 \%$ stood in front of the panhandler (distributed across the conditions), and $1 \%$ (one in the female only and one in the male only condition) turned around when approaching the panhandler. Eye contact was made by $27.5 \%$ of the pedestrians; although the frequency varied by condition ( $24 \%$ female only, $36 \%$ male only, $8 \%$ male dyad, $34 \%$ female/male dyad) it was not significant, Fisher's exact test $=6.582, p=.09$ (note that the cell sizes did not warrant the Monte Carlo approximation). Pedestrian's gait speed increased for 39.5\% of the sample, while it slowed for $38.5 \%$; this change was distributed across the conditions and not significant (speed increase, Fisher's exact test $=6.686, p=.348$; speed decrease Fisher's exact test $=4.999, p=.541$; approximation again not necessary).

\section{DISCUSSION}

Past observational research indicates that men alter their behavior in the presence of women (e.g., Wilson \& Daly, 2004). The aim of the current study was to investigate men's displays of resources in the presence versus absence of women, using the framework of evolved mate preferences. We hypothesized that men would donate money or other items most often in the presence of women, compared to while walking alone or in the presence of other men. Our hypothesis was supported. We argued that men engage in this behavior as a signal to potential mates about their personality characteristics of kindness and generosity, as well as their current level of resources or wealth. There exists a large corpus of research that shows women generally favor men with these traits, at least in terms of self-report data (e.g., Buss, 1989; Buss \& Schmitt, in press; Hunter, Hill, Reid, Bourgeois, \& Fisher, in review).

It is key to note that simply the presence of another individual does not lead to the same outcome. Men walking with another man gave significantly fewer items to panhandlers than when walking with a woman, and hence, we conclude that it is not merely the presence of another person that prompts this behavior. While walking with another male, men do not need to demonstrate generosity or their ability to allocate resources, which supports our conjecture that this behavior is a display to gain favor with potential mates. The behavior is also not specific to men, as we found men gave items to panhandlers as often as women when walking alone, and that it remained significantly less frequent than the behavior of men in the mixed sex dyads.

Our findings align with those of Iredale, Van Vugt, and Dunbar (2008). In an experimental game situation, men were more likely to donate a larger portion of their earned winnings to charity when observed by women, than when observed by men or when not observed. The researchers attributed this finding to costly signaling, such that generosity may indicate traits such as kindness and helpfulness. More recently, Van Vugt and Iredale (2013) replicated this effect, finding groups of men donated more in public good games when there was a female audience, and that men's donations positively increased according to their rating of the women's attractiveness. 
We note that our observations occurred during the winter months in Canada, but effort was taken to ensure that the weather conditions as well as other contextual issues (e.g., time of day, day of the week, temperature) were as close to possible as identical across the days in which we collected our data. It may be informative to replicate this study when the weather is warmer, given that pedestrians may behave more leisurely and be more interactive due to the higher temperature. Ambient temperature is key, as Vanky and colleagues (2017) findings do not support the potential of a merely seasonality effect. They gathered GPS data from a mobile telephone tracking application for almost 250000 trips over 50 weeks by 13688 individuals living in Boston or San Francisco. They report that regardless of seasonality, ambient air temperature and cloud cover predict trip frequency, particularly for weekend (and they argue presumably discretionary) travel. However, weather had minimal impact on the duration of trips, once a trip was initiated.

One limitation concerns the assumption of pedestrian's sexual orientation. The design of this research dictated that we assumed all female/male dyads involved heterosexual individuals, and that the male/male dyads did not involve displays of mating-relevant signals. These assumptions, of course, are likely not accurate. Further research is needed to examine how sexual orientation plays a role in the same sorts of behaviours observed in this study. Moreover, we do not know the relationship of those involved in the dyads; it could be that the female/male dyads were romantic partners or siblings, for example, which likely influences the results and their implications.

Another limitation is that we did not include data from female/female dyads. This exclusion was due to the focus of the current work on male displays. However, for completeness, it would be potentially informative to include female/female dyads. We also could have considered sex of the panhandlers more fully, although observation suggests that in Halifax, the location of the study, the overwhelming majority of panhandlers are men. Goldberg (1995) performed a similar study to the current research and documented that men, when alone, were more likely to donate items to female than male panhandlers. They also report that men, when accompanied by similarly aged women, seemed to avoid giving items to female panhandlers and did not give disproportionately more to male panhandlers, which the author interpreted as men avoiding "showing off." Different results were found decades earlier by Latane (1970) who recorded men were more likely to provide assistance (i.e., tell the time, provide directions, or give money) than women, and women were more likely to receive help than men.

The findings of the current study indicate that naturalistic observation of real-world events may be useful for understanding mate preferences that are typically documented via self-report surveys. We showed that men are most likely to signal their resources as well as generosity and kindness in the presence of women, which suggests that they may have an awareness of female mate preferences and perform these actions in order to be viewed in a positive manner. 


\section{REFERENCES}

Andersson, M. B. (1994). Sexual selection. Princeton, NJ: University Press.

Buss, D. M. (1989). Sex differences in human mate preferences: Evolutionary hypotheses tested in 37 cultures. Behavioural and Brain Sciences, 12, 1-49. DOI

Buss, D. M., \& Schmitt, D. P. (2019). Mate preferences and their behavioral manifestations. Annual Review of Psychology, 70, 77-110. DOI

Buss, D. M., \& Schmitt, D. P. (1993). Sexual strategies theory: An evolutionary perspective on human mating. Psychological Review, 100(2), 204-232. DOI

Campbell, A. (1999). Staying alive: Evolution, culture, and women's intrasexual aggression. Behavioral and Brain Sciences, 22(2), 203-214. DOI

Clifford, S., \& Piston, S. (2017). Explaining public support for counterproductive homelessness policy: The role of disgust. Political Behavior, 39(2), 503-525. DOI

Darwin, C. (1871). The descent of man, and selection in relation to sex. London: John Murray. DOI

Dordick, G., O'Flaherty, B. A., Brounstein, J., Sinha, S., \& Jungsoo, Y. (2017). What happens when you give money to panhandlers? The case of downtown Manhattan. Columbia University Report. DOI

Fisher, M., Garcia, J., \& Burch, R. (upcoming). Evolutionary psychology: Thoughts on integrating feminist perspectives. In L. Workman, W. Reader, \& J. Barkow (Eds.), Cambridge handbook of evolutionary perspectives on human behavior. Cambridge: Cambridge University Press.

Goldberg, T. L. (1995). Altruism towards panhandlers: Who gives? Human Nature, 6(1), 79-89. $\underline{\text { DOI }}$

Hunter, H., Hill, T., Reid, G., Bourgeois, C., \& Fisher, M. (in review). Hi, my name is wealthy: Women's dating behaviors in relation to the perceived wealth of perspective mates.

Iredale, W., Van Vugt, M., \& Dunbar, R. (2008). Showing off in humans: Male generosity as a mating signal. Evolutionary Psychology, 6(3), 386-392. DOI

Kordsmeyer, T. L., Hunt, J., Puts, D. A., Ostner, J., \& Penke, L. (2018). The relative importance of intra- and intersexual selection on human male sexually dimorphic traits. Evolution and Human Behavior, 39(4), 424-436. DOI

Latane, B. (1970). Field studies on altruistic compliance. Representative Research in Social Psychology, 1(1), 49-61.

Lee, B. A., \& Farrell, C. R. (2003). Buddy, can you spare a dime? Homelessness, panhandling, and the public. Urban Affairs Review, 38(3), 2990324. DOI

Lu, H. J., Zhu, X. Q. \& Chang, L. (2015). Good genes, good providers, and good fathers: Economic development involved in how women select a mate. Evolutionary Behavioral Sciences, 9(4), 215-228. DOI

Pandey, J., Bharti, P., Verma, S., Shukla, A., Punita, C., Upadhyay, I., ... Tripathi, N. (2006). Stigmatized and marginalized group identity and coping. Presented in the 26th international congress of applied psychology. Athens: Greece.

Tsai, J., Lee, C. Y. S., Byrne, T., Pietrzak, R. H., \& Southwick, S. M. (2017). Changes in public attitudes and perceptions about homelessness between 1990 and 2016. American Journal of Community Psychology, 60(3-4), 599-606. DOI

Trivers, R. (1972). Parental investment and sexual selection. In B. Campbell (Ed.), Sexual selection and the descent of man (pp. 136-179). Chicago, IL: Aldine-Atherton. DOI

Van Vugt, M., \& Iredale, W. (2013). Men behaving nicely: Public goods as peacock tails. British Journal of Psychology, 104(1), 3-13. DOI 
Vanky, A. P., Verma, S. K., Courtney, T. K., Santi, P., \& Ratti, C. (2017). Effect of weather on pedestrian trip count and duration: City-scale evaluations using mobile phone application data. Preventive Medicine Reports, 8, 30-37. DOI

Verma, S. K., Bharti, P., \& Singh, T. (2018). Does stigma always have negative consequences? Journal of Community and Applied Social Psychology, 28(6), 495-507. DOI

Walters, S., \& Crawford, C. B. (1994). The importance of mate attraction for intrasexual competition in men and women. Evolution and Human Behavior, 15(1), 5-30. DOI

Wilson, M., \& Daly, M. (2004). Do pretty women inspire men to discount the future? Proceedings of the Royal Society of London. Series B: Biological Sciences, 271, 177-179. DOI 